\title{
Mechanical Properties and Sliding Wear Resistance of Suspension Plasma Sprayed YSZ Coatings
}

\author{
Leszek Łatka', Mirosław Szala ${ }^{2 *}$, Wojciech Macek ${ }^{3}$ and Ricardo Branco ${ }^{4}$ \\ 1 Faculty of Mechanical Engineering, Wrocław University of Science and Technology, Łukasiewicza 5, Wrocław \\ 50-371, Poland \\ 2 Department of Materials Engineering, Faculty of Mechanical Engineering, Lublin University of Technology, \\ Nadbystrzycka 36D, Lublin 20-618, Poland \\ 3 University of Occupational Safety Management in Katowice, Bankowa 8, 40-007 Katowice, Poland \\ ${ }^{4}$ University of Coimbra, CEMMPRE, Department of Mechanical Engineering, Rua Luís Reis Santos, Pinhal de \\ Marrocos, 3030-788 Coimbra, Portugal \\ * Corresponding author's e-mail:m.szala@pollub.pl
}

\begin{abstract}
In this work, the yttria stabilised zirconia $\mathrm{ZrO}_{2}+8 \mathrm{wt} \% \mathrm{Y}_{2} \mathrm{O}_{3}$ (YSZ) coatings were studied. The coatings were manufactured by using a relatively new method based on liquid feedstock, called suspension plasma spraying (SPS). The main aim of the study was to investigate the influence of one of the fundamental process parameters, stand-off distance, on the YSZ coating mechanical properties, namely adhesion, cohesion, hardness, and dry sliding wear resistance. Moreover, the coating surface morphology and microstructure were investigated. Despite the fact that in the SPS method, the heat flux into the substrate is much higher than in conventional atmospheric plasma spraying (APS), for the stand-off distances as short as $40 \mathrm{~mm}$, the structure has not been damaged by thermal stresses. The results revealed that shorter spray distance leads to obtaining the coatings characterised by higher cohesion and adhesion to the substrate as well as higher hardness and resistance to sliding wear. The wear mechanism of both YSZ coatings relies on the adhesive mode, which is intensified by severe coating material delamination.
\end{abstract}

Keywords: suspension plasma spraying, yttria, stabilised zirconia, microstructure, hardness, sliding, wear, adhesion, thermal spraying, ceramic

\section{INTRODUCTION}

Among many techniques in the area of surface engineering, the thermal spraying methods are most frequently used in industrial applications. The main idea is heating of the feedstock material (in the form of powder, wire, or rods) by flame, electric, or plasma arcs. Then, the molten particles are accelerated towards the substrate and create the coating layer by layer [1-3]. Plasma spraying is the most common method among the thermal spray techniques. Temperature could be as high as $20000 \mathrm{~K}$, and the velocity of the particles may achieve as much as $800 \mathrm{~m} / \mathrm{s}$. The electrical arc is ignited between the tungsten cathode and copper anode. The versatility of plasma spray processes allows manufacturing different types of feedstock materials. Usually, ceramic [4], metallic [5], polymer [6], or composite [7] coatings are deposited. In the case of plasma powder spraying, the feedstock material particle size ranges from $20 \mu \mathrm{m}$ to $90 \mu \mathrm{m}[8,9]$. Therefore, the conventional plasma-sprayed powder coatings, as well as atmospheric plasma spraying (APS), consisting of coarse grain-size microstructure and nanostructure deposits cannot be manufactured and the modern spray method such as suspension plasma spraying (SPS) should be employed.

The nanostructured materials have been studied extensively, starting from the 1990s. The nanostructured coatings present especially outstanding mechanical, electrical, physical, 
and optical properties. According to a definition, the nanostructured materials have crystals smaller than $100 \mathrm{~nm}$ [10]. It is known that the nano-size microstructure effects on the modification of material properties [11]. Strengthening of metallic materials results from the fact that the nanophase microstructure is nearly dislocation-free. Improvement of nanostructured materials in strength, resistance to wear and thermal shock, and reduction of micro-cracking, caused an increasing interest in the research and possible applications of such materials [12]. Overall, the mechanical properties are dependent on the presence of defects in material or its plasticity. Initiation of defects is much more difficult when grain dimensions are fine. It results in a change of the mechanical properties. Generally, the plasticity or ductility results from a number of grain size and density of interfacial boundaries $[10,12]$. Generally, the microstructure refinement increases the mechanical properties of engineering materials.

One of the fastest growing branches of nanoscience is surface engineering. The coatings based on nanostructured materials are mainly produced using the vapour condensation methods, such as physical vapour deposition, chemical vapour deposition and similar methods [13]. However, these methods allow obtaining a rather thin coating, with thickness generally not greater than a few micrometres. Moreover, the deposition rate is relatively low, and the processes are cost-demanding. On the other hand, the conventional thermal spraying techniques, especially plasma spraying, allow deposition of thick coatings, even over $1 \mathrm{~mm}$, with good efficiency. However, these coatings do not have a nanostructured architecture [8-10].

Therefore, novel spray techniques for manufacturing the nanostructured coatings are being systematically developed. However, the different issues with the materials deposition-technological parameters had to be solved beforehand. The crucial problems relate to transporting and feeding of fine and dry particles, even in submicrometric range, smaller than $10 \mu \mathrm{m}$. In addition, injection of such small powder particles and penetration of jet or flame implies difficulties. This results from the smaller mass of particles and, consequently, lower momentum and results in the fact that fine particles are moved in the colder and outer zones of the plasma jet. One solution to this problem was proposed using greater carrier (transport) gas flow rate. It was, however, not practical because it resulted in cooling of the plasma jet $[11,11,14]$. A completely different solution was proposed by a group from Sherbrooke University, about fifteen years ago. They developed a new technique, in which fine particles are transported into the plasma jet, or flame, by liquid transport media, such as suspension or solution [15]. In this technique, the liquid including solid fraction is injected into the hot temperature zone of the plasma jet. Suspension and solution thermal spraying (SPS) techniques allow obtaining finely structured, even nanostructured, coatings with thickness from a few up to hundreds of micrometers $[1,8,10,11]$. More information about the important process parameters, as well as the detailed description are given in [16]. The area of potential applications of SPS coatings is very wide and could be found in: (i) thermal barrier coatings $[17,18]$, (ii) solid oxy-fuel cells $[19$, 20], (iii) biomedical [21, 22], wear resistance $[23,24]$ and (v) photocatalytic surfaces $[25,26]$.

On the basis of literature review, it can be stated that from the wide range of SPS materials, the yttria stabilised zirconia (YSZ) is the most examined feedstock material [27-29]. Moreover, the depiction procedure of the YSZ is being systematically developed. It is known that the thermal spray parameters strongly affect the properties of the coatings. Therefore, in our study, we used and attempted to investigate the coatings obtained with the untypical injection mode (radial and internal), which could result in good thermal treatment of the coatings material. Therefore, to preliminarily investigate the elaborated usage of the specific plasma torch, we studied the coatings deposited with different spray distance. For this reason, the paper analysed the microstructure, mechanical properties and dry-sliding wear resistance of the YSZ coatings manufactured by SPS.

The main aim of the study was to investigate the influence one of the fundamental SPS process parameters, namely stand-off distance, on the YSZ coating mechanical properties, such as adhesion, cohesion, hardness and dry sliding wear resistance.

\section{EXPERIMENT DESIGN}

\section{Suspension preparation and spray parameters}

The commercially available powder Metco 204 NS (Oerlikon Metco, Pfaffikon, Switzerland) of $\mathrm{ZrO}_{2}+8 \mathrm{wt} \% \mathrm{Y}_{2} \mathrm{O}_{3}$ (YSZ) was used. 
For the formulation of liquid feedstock, coarse powder was crushed in an EMax device ball milling (Retsch GmbH, Haan, Germany) in order to obtain the monomodal particles size distribution with average diameter $\mathrm{d}_{\mathrm{vS} 50}$ approximately equal to $1 \mu \mathrm{m}$. The solid content in suspension was equal to $20 \mathrm{wt} \%$. A liquid phase was a mixture of distilled water and ethanol in the mass ratio 1:1.

The coatings were manufactured by means of the SPS method. Suspension plasma spraying (SPS) was carried out with the use of SG-100 one cathode, one anode plasma torch, which was mounted on the 6 axis Fanuc 2000 IA industrial robot. The mixture of plasma gases consisted of argon and hydrogen. The suspension was injected radially and in internal mode through the nozzle with the diameter equal to $0.5 \mathrm{~mm}$. All process parameters are collected in Table 1.

Table 1. Technological parameters of suspension thermal spraying

\begin{tabular}{|c|c|c|}
\hline $\begin{array}{ll} & \text { Sample code } \\
\end{array}$ & YSZ40 & YSZ60 \\
\hline Stand-off distance, $\mathrm{mm}$ & 40 & 60 \\
\hline $\begin{array}{l}\text { Plasma gases composition and its flow } \\
\text { rate, slpm* }\end{array}$ & \multicolumn{2}{|c|}{$\mathrm{Ar}-45+\mathrm{H}_{2}-5$} \\
\hline Electrical power, kW & \multicolumn{2}{|c|}{40} \\
\hline Suspension feed rate, $\mathrm{g} / \mathrm{min}$ & \multicolumn{2}{|c|}{39} \\
\hline Torch velocity, $\mathrm{mm} / \mathrm{s}$ & \multicolumn{2}{|c|}{500} \\
\hline
\end{tabular}

* slpm - standard liter per minute.

Coatings were deposited onto the stainless steel substrate grade X2CrNiMo17-12-2 according to the PN-EN 10088-1:2014-12 standard (AISI 316L), with $25 \mathrm{~mm}$ in diameter and $6 \mathrm{~mm}$ in thickness. Before spraying, the substrate surface was sand-blasted with corundum grit (F80 according to the FEPA standard) under the pressure equal to $0.4 \mathrm{MPa}$ from a distance about 100 $\mathrm{mm}$. Then, the substrates were cleaned in ultrasonically assisted ethanol bath.

\section{Microstructure and morphology analysis}

The free surfaces of coatings and their crosssections were investigated by SEM JEOL JSM $5800 \mathrm{LV}$ scanning electron microscope (JEOL Ltd., Akishima, Japan) to observe the microstructural features of deposits. The main aim was to determine the morphology of coatings, including the degree of melting of the particles, appearance of microcracks and voids, etc. On the cross section, the measurements of the thickness of the coatings were carried out at 500x magnification in 10 random locations. On the other hand, at 1000x magnification, the porosity was evaluated by image analysis, according to the ASTM E2109-01 Standard. The roughness of coatings was measured by Surtronic S-128 stylus profilometer, Taylor-Hobson. The mean values of the Ra, Rz, and Rt parameters were calculated according to the formulas presented in previous papers [30, 31]. Five measurements on each sample were carried out and average and standard deviation (SD) were determined.

\section{MECHANICAL PROPERTIES}

The mechanical testing of the yttria stabilised zirconia (YSZ) coatings deposited with suspension plasma spraying (SPS) was divided into two sections: adhesion, cohesion, hardness testing and dry sliding wear resistance testing.

\section{Adhesion, cohesion and hardness}

The coatings adhesion strength, as well as cohesion in the coating, were carried out in the Micro Combi Tester (Anton Paar, Graz, Austria) equipped with Rockwell diamond indenter with a tip radius equal to $0.1 \mathrm{~mm}$. The tests were performed in accordance with the ASTM C1624-05 standard [32]. In the adhesion strength, three tests were carried out. The scratches were linear with progressively increasing load from $0 \mathrm{~N}$ up to 30 $\mathrm{N}$. In this work, the critical load $F_{c}$ was defined as the beginning of visibility of metallic substrate inside the scratch channel. On the other hand, for the scratch hardness $\left(H S_{L}\right)$ determination, the load was fixed on the constant level equal to 15 $\mathrm{N}$. Then, the scratch width was measured in three different locations. The $H S_{L}$ values were calculated according to the ASTM G171-03 standard based on equation (1) [33] :

$$
H S_{L}=\frac{8 \cdot F}{\pi \cdot d^{2}}[\mathrm{MPa}]
$$

where: $F$-applied normal load, N

$d$ - corresponding scratch width, $\mathrm{mm}$

Instrumental indentation tests (IIT) were performed with the use of an NHT3 nanoindenter (Anton Paar, Graz, Austria) on the polished cross sections of coatings. The procedure corresponded to the ATSM E2546 standard. In the measurements, the Berkovich indenter was 
used. The maximum load $\left(\mathrm{P}_{\max }\right)$ value used in IIT was equal to $200 \mathrm{mN}$. The loading and unloading force was twice greater than the value of $\mathrm{P}_{\max }$ and the dwell time was equal to $15 \mathrm{~s}$. The indentation hardness values were determined by Oliver-Pharr method [34, 35].

\section{Dry sliding wear resistance}

The dry sliding wear tests were carried out in rotating unidirectional configuration according to the ASTM G99-17 Standard using a CSM Instruments tribometer (CSM Instruments SA, 2034 Peseux, Switzerland). The WC counter body with the diameter of $6 \mathrm{~mm}$ was used. The applied load, sliding speed and sliding distance were as follows: $10 \mathrm{~N}, 0.1 \mathrm{~m} / \mathrm{s}$, and $1000 \mathrm{~m}$, respectively. The wear rate $(W R)$ was calculated from the wear formula of Lancaster [36]:

$$
W R=\frac{V_{\text {wear }}}{F_{N} \cdot S}\left[\mathrm{~mm}^{3} \cdot \mathrm{N}^{-1} \cdot \mathrm{m}^{-1}\right]
$$

where: $V_{\text {wear }}$-volume loss, $\mathrm{mm}^{3}$

$F_{N}-$ normal load, $\mathrm{N}$

$S$-sliding distance, $\mathrm{m}$

\section{RESULTS AND DISCUSSION}

\section{Coatings microstructure and surface morphology}

The surfaces of sprayed coatings are shown in Figure 1, whereas their cross-sections are presented in Figure 2. It can be observed that the microstructure of the obtained coatings is not uniform. It is created by well-molten lamellas, separated by the areas consisting of sintered powder particle agglomerates which did not melt completely. It is a so-called two-zone microstructure, characteristic for the technique of suspension plasma spraying [37].

The microcracks visible on the surfaces of the sprayed coatings (Fig. 1) are supposedly caused by the thermal stresses resulting from a short spraying distance in the SPS method comparing to the traditional APS (atmosphere plasma spray) method. Upon observing the cross-sections of the coatings (Fig. 2) it can be noted that the YSZ60 sample has more pores, which indicates that decreasing the spraying distance allows obtaining a denser coating structure containing more wellmelted lamellas.

On the basis of the measurements, the following thicknesses and the roughness of the coating were obtained. The results are shown in Table 2. The YSZ coating sprayed with $40 \mathrm{~mm}$ stand-off distance results in average thicker coatings which can be explained by the higher heat input that results in a higher rate of feedstock material deposition. However, the analysis pertaining to the deviations of the roughness parameters and thickness indicates that both values were at a comparable level.

\section{Hardness, adhesion and cohesion}

The hardness of the YSZ40 and YSZ60 coatings equals, $3.1 \pm 0.5 \mathrm{GPa}$ and $2.2 \pm 0.6 \mathrm{GPa}$, respectively. Higher hardness of YSZ40 can be
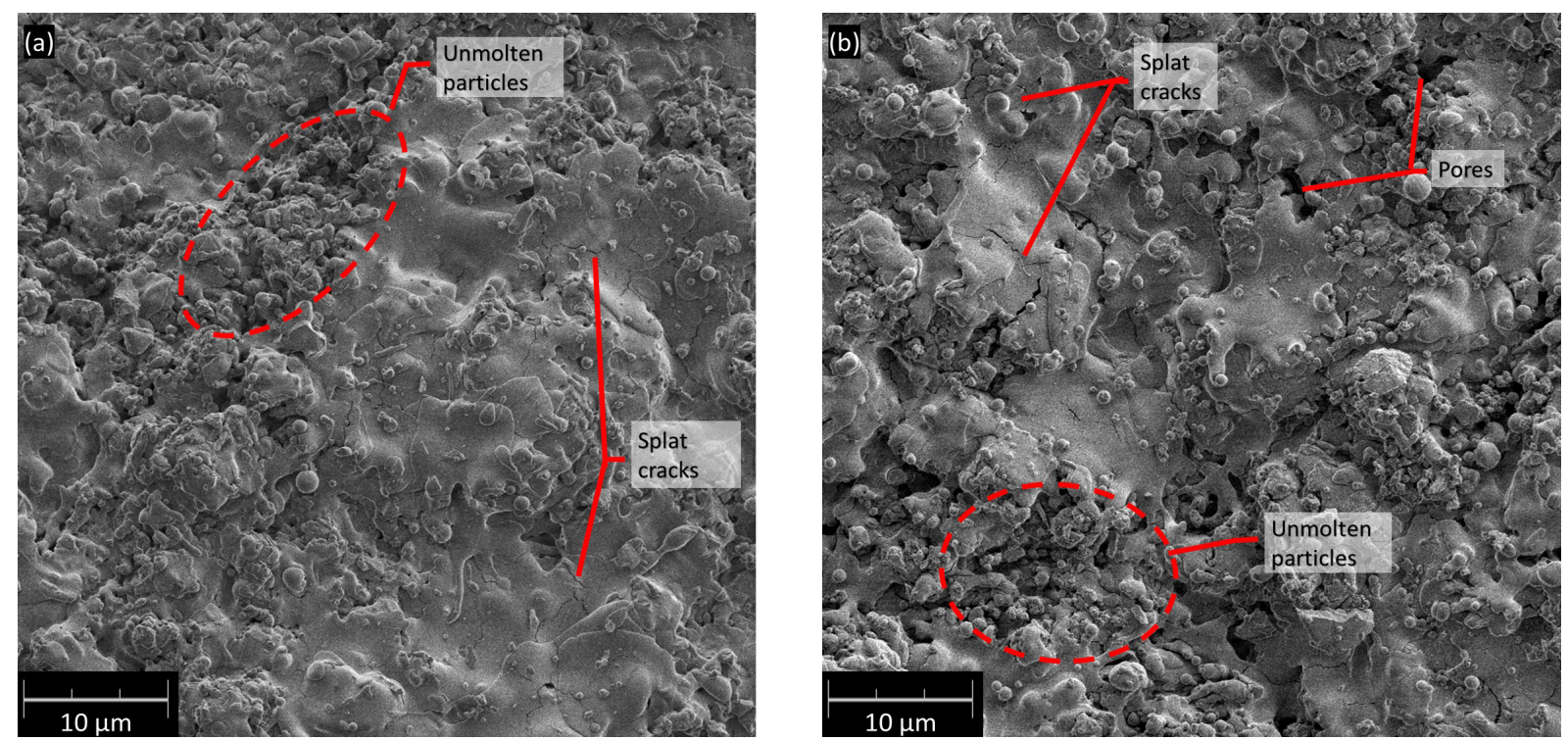

Fig. 1. Surface morphology of the YSZ40 (a) and YSZ60 (b) coatings 

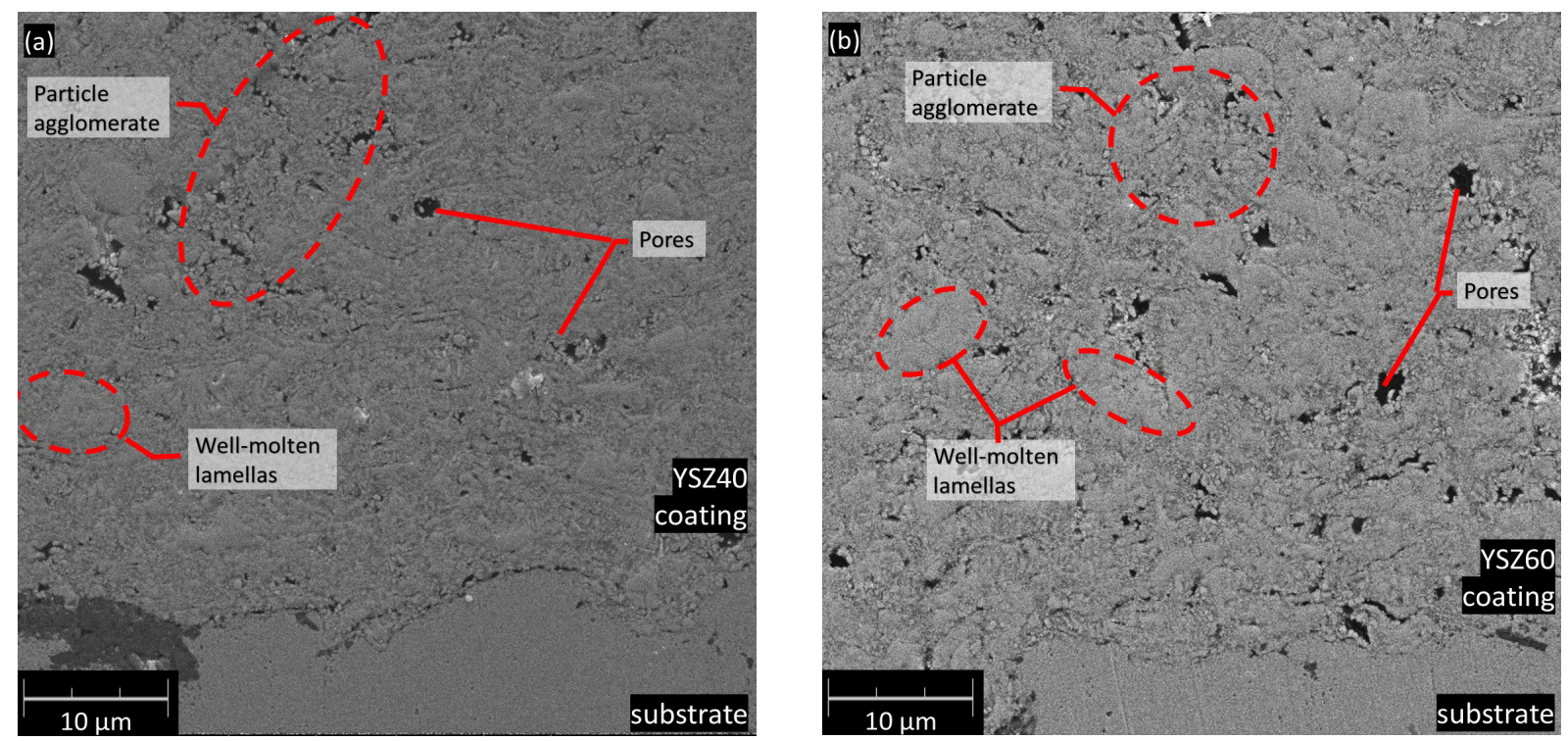

Fig. 2. Cross-sectional microstructure: YSZ40 (a) and YSZ60 (b)

Table 2. Thickness and roughness of the as-deposited SPS coatings, mean \pm SD

\begin{tabular}{|c|c|c|c|c|}
\hline \multirow{2}{*}{ Coating } & \multirow{2}{*}{ Thickness, $\mu \mathrm{m}$} & \multicolumn{3}{|c|}{ Surface roughness parameter, $\mu \mathrm{m}$} \\
\cline { 3 - 5 } & & $\mathrm{R}_{\mathrm{a}}$ & $\mathrm{R}_{\mathrm{z}}$ & $\mathrm{R}_{\mathrm{t}}$ \\
\hline YSZ-40 & $62 \pm 6$ & $3.04 \pm 0.47$ & $11.16 \pm 2.79$ & $15.44 \pm 3.86$ \\
\hline YSZ-60 & $58 \pm 5$ & $2.85 \pm 0.75$ & $10.44 \pm 2.93$ & $14.77 \pm 3.61$ \\
\hline
\end{tabular}

explained by the denser microstructure, which is a result of shorter spray stand-off. The hardness is in the range reported by our previous study [38] for the yttria stabilised zirconia coatings. The tests on adhesion in coatings revealed significant differences in the results for the analysed coatings. In the case of the YSZ40 sample, the values of critical load $\mathrm{F}_{c}$ exceeded $28 \mathrm{~N}$, whereas in the case of the YSZ60 sample the value of $20 \mathrm{~N}$ was not reached (Fig. 3). It is to be stated that the damage of the coating material took place only in a small area. In the whole scratch, the complete delamination was not observed.

In the case of testing the cohesion describing parameter in coatings, a similar tendency to the case of adhesion was observed, mainly that for a coating sprayed from a shorter distance (YSZ40) the value of the cohesion parameter $\left(\mathrm{HS}_{\mathrm{L}}\right.$ ) is greater than in the case of YSZ60 (Fig. 4). The differences between the coatings cohesion are not as significant as it was in the case of critical load noted in the adhesion tests. However, the surface coated from a shorter distance has a higher value of the $\mathrm{HS}_{\mathrm{L}}$ than YSZ60 coating. This indicates that it is more resistant to delamination throughout its entire volume.

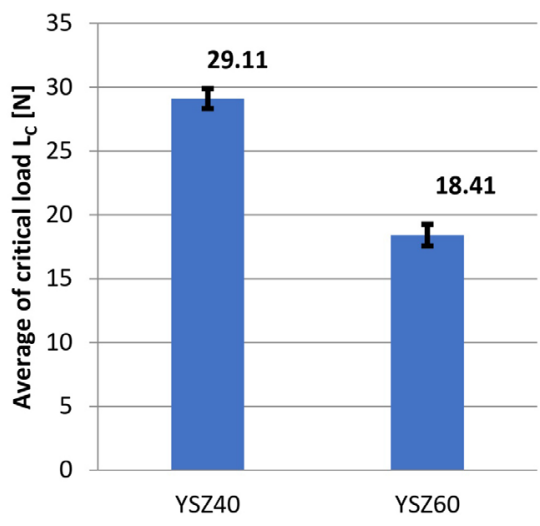

Fig. 3. Comparison of average values of critical load for the YSZ40 and YSZ60 samples

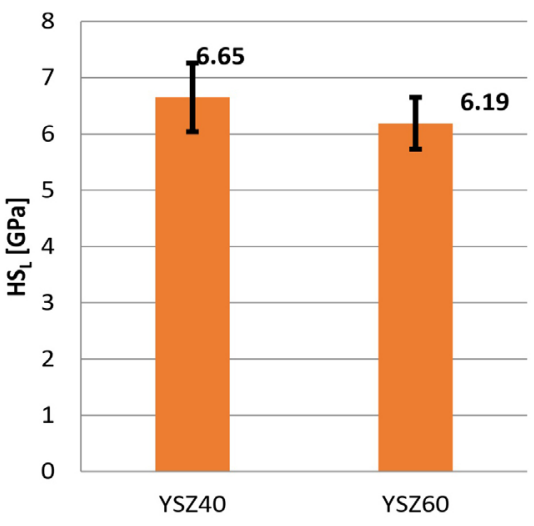

Fig. 4. Comparison of HSL cohesion parameter of YSZ40 and YSZ60 coatings 
Table 3. Dry sliding wear results of YSZ coatings, mean \pm SD

\begin{tabular}{|c|c|c|}
\hline Sample & $\begin{array}{c}\text { Wear rate, } \\
W R, \times 10^{-6} \mathrm{~mm}^{3} \cdot \mathrm{N}^{-1} \cdot \mathrm{m}^{-1}\end{array}$ & $\begin{array}{c}\text { Friction } \\
\text { coefficient, } f\end{array}$ \\
\hline YSZ40 & $3.2 \pm 0.4$ & $0.48 \pm 0.06$ \\
\hline YSZ60 & $3.6 \pm 0.4$ & $0.55 \pm 0.07$ \\
\hline
\end{tabular}

\section{Wear behaviour}

The results of sliding wear resistance of coatings are shown in Table 3. The friction coefficient for both coatings is at comparable level, but YSZ40 gives the lowest average value of 0.48 . Consequently, it can be claimed that the YSZ40 coating presents slightly higher wear resistance indicated by the lower mean WR and lower friction coefficient. This is a result of better adhesion, cohesion properties of YSZ40 than for YSZ60. Moreover, the friction coefficient is obtained in a wide range, and this can be explained by the coatings cohesion and non-uniform coatings microstructure that consist of well-molten lamellas and sintered agglomerates of the YSZ coating material. Summing up, the results given in Table 3 indicate a relatively high wear resistance of both YSZ coatings. In comparison to the recent results reported by our research group [39-45] for metallic materials, coatings and surface treatments, the overall wear resistance of the YSZ coatings can be classified as comparable to the alumina-based ceramic coating, rather than bulk metal alloys, composite coatings or metallic coatings. On the other hand, it is to be mentioned that similar results were obtained for typically submicrometric coatings, also with yttria

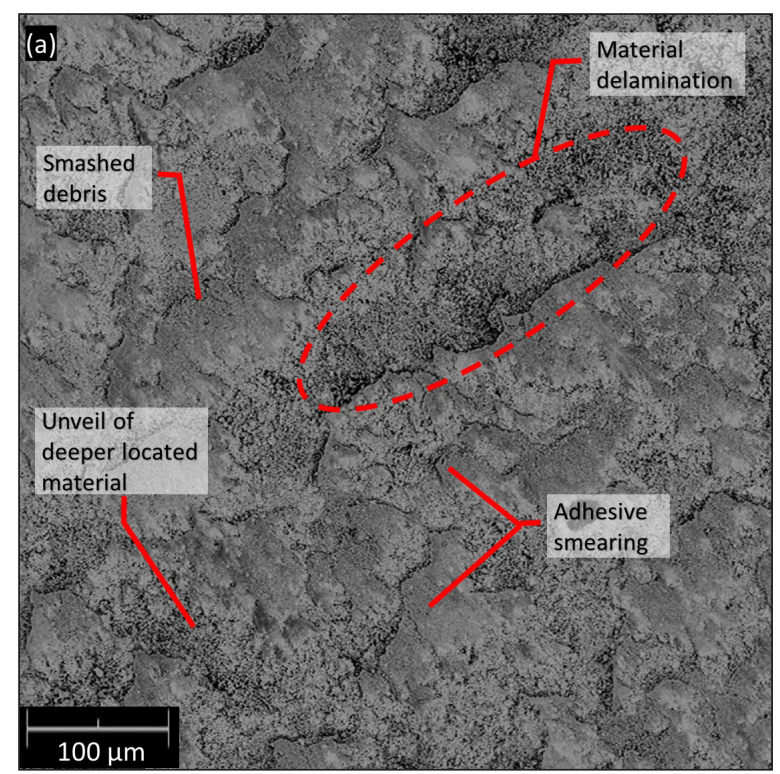

stabilised zirconia oxide as the output material, but with the grain size c.a. $400 \mathrm{~nm}$. These coatings were also suspension plasma sprayed [46].

The sliding wear mechanism of the YSZ ceramic coatings is presented in Figure 5. The analysis of the wear mechanism indicates that both coatings show a comparable wear mode, namely the adhesive wear mechanism dominates. The adhesion relies on transferring the coating material by the counterbody ball. The adhesive damage is facilitated by the secondary wear mechanism that works on severe delamination of the coating material and exposition of a more in-depth located material. Figure $5 \mathrm{~b}$ presents the exposed coating initial structure that consists of the YSZ particle. Loose debris produced by delamination is transferred and smashed thorough the wear track. It is known from literature that the adhesive wear mode usually results in a high wear rate $[47,48]$.

\section{CONCLUSIONS}

The goal of the study was to investigate the influence of the suspension plasma spraying (SPS) process parameter, namely stand-off distance (40 $\mathrm{mm}$ and $60 \mathrm{~mm}$ ), on the $\mathrm{ZrO}_{2}+8 \mathrm{wt} \% \mathrm{Y}_{2} \mathrm{O}_{3}$ (YSZ) coating adhesion, cohesion, hardness and dry sliding wear resistance. The distance from which the SPS coating is sprayed is significant for the microstructure and mechanical properties. The results of the study lead to the following conclusions:

1 . The shorter distance, the more promising mechanical properties and microstructure. The

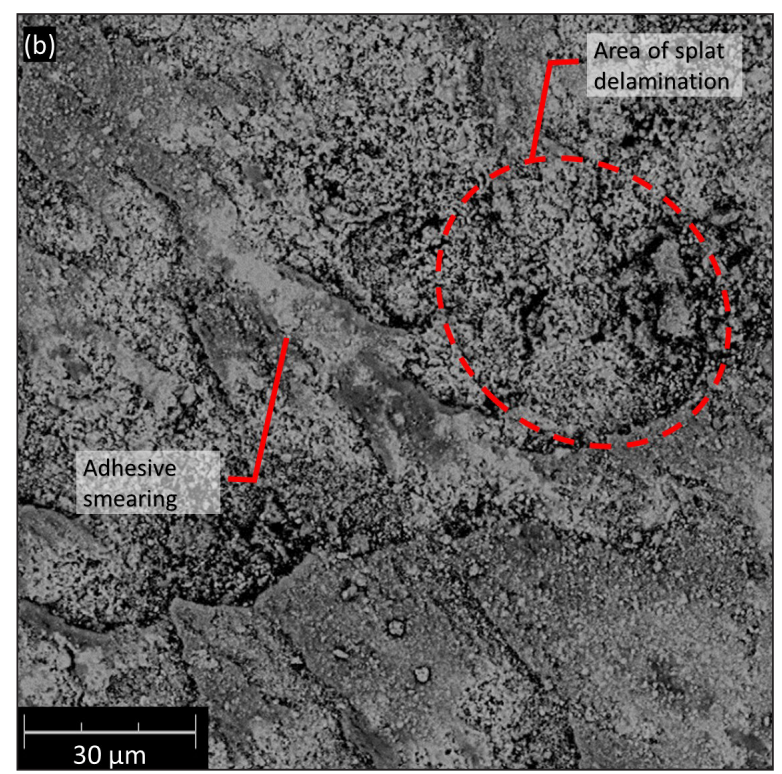

Fig. 5. Wear traces of the YSZ40 (a) and YSZ60 (b) coatings, SEM 
research indicated that in the case of both coatings, a two-zone microstructure typical for the SPS method, was obtained. However, the YSZ40 coating was characterised by a smaller number of unmelted particles in the form of sintered agglomerates.

2. Moreover, upon comparing the YZS40 and YSZ60 samples, it was observed that the YSZ40 coating has higher average adhesion, cohesion and hardness, denser microstructure as well as lower wear rate than the YSZ60 coating.

3. The YSZ coating sprayed from $40 \mathrm{~mm}$ stand-off distance presents a higher wear resistance than that deposited from $60 \mathrm{~mm}$. The YSZ40 wear rate and friction coefficient was equal to $3.2 \times 10^{6}$ $\mathrm{mm}^{3} \cdot \mathrm{N}^{1} \cdot \mathrm{m}^{1}$ and $0.48 \pm 0.06$, respectively.

4. The analysis of the dry sliding wear mechanism of the YSZ coatings allows stating that for both coatings it relies on the adhesive mode, which is intensified by the severe coating material delamination.

\section{Acknowledgement}

The research was financed in the framework of the project Lublin University of TechnologyRegional Excellence Initiative, funded by the Polish Ministry of Science and Higher Education (contract No. 030/RID/2018/19).

\section{REFERENCES}

1. Pawlowski L. The Science and Engineering of Thermal Spray Coatings. 2nd Edition. Chichester, England ; Hoboken, NJ: Wiley; 2008. 656 p.

2. Heimann RB. Plasma Spray Coating: Principles and Applications. 2nd Edition. Weinheim: WileyVCH; 2008. 449 p.

3. Fauchais P, Montavon G, Bertrand G. From Powders to Thermally Sprayed Coatings. J Therm Spray Technol. 2010;19(1):56-80.

4. Kiilakoski J, Langlade C, Koivuluoto H, Vuoristo P. Characterizing the micro-impact fatigue behavior of APS and HVOF-sprayed ceramic coatings. Surf Coat Technol. 2019;371:245-54.

5. Alontseva D, Krasavin A, Prokhorenkova N, Kolesnikova T. Plasma-Assisted Automated Precision Deposition of Powder Coating Multifunctional Systems. Acta Phys Pol A. 2017;132(2):233-5.

6. Gonzalez R, Ashrafizadeh H, Lopera A, Mertiny P, McDonald A. A Review of Thermal Spray Metallization of Polymer-Based Structures. J Therm Spray Technol. 2016;25(5):897-919.
7. Maruszczyk A, Dudek A, Szala M. Research into Morphology and Properties of TiO2 - NiAl Atmospheric Plasma Sprayed Coating. Adv Sci Technol Res J. 2017;11(3):204-10.

8. Fauchais PL, Heberlein JVR, Boulos M. Thermal Spray Fundamentals: From Powder to Part. Springer US; 2014. 2481 p.

9. Lima RS, Marple BR. Thermal Spray Coatings Engineered from Nanostructured Ceramic Agglomerated Powders for Structural, Thermal Barrier and Biomedical Applications: A Review. J Therm Spray Technol. 2007;16(1):40-63.

10. Gan JA, Berndt CC. Nanocomposite coatings: thermal spray processing, microstructure and performance. Int Mater Rev. 2015;60(4):195-244.

11. Killinger A, Gadow R, Mauer G, Guignard A, Vaßen R, Stöver D. Review of New Developments in Suspension and Solution Precursor Thermal Spray Processes. J Therm Spray Technol. 2011;20(4):677.

12. Makhlouf A, Scharnweber D, redaktorzy. Handbook of Nanoceramic and Nanocomposite Coatings and Materials. 1st Edition. Amsterdam: Butterworth-Heinemann; 2015. 612 p.

13. Pawlowski L. Finely grained nanometric and submicrometric coatings by thermal spraying: A review. Surf Coat Technol. 2008;202(18):4318-28.

14. Fan W, Bai Y. Review of suspension and solution precursor plasma sprayed thermal barrier coatings. Ceram Int. 2016;42(13):14299-312.

15. Gitzhofer F, Bouyer E, Boulos MI. Suspension plasma spray [Internet]. US5609921A, 1997.

16. Łatka L. Thermal Barrier Coatings Manufactured by Suspension Plasma Spraying - A Review. Adv Mater Sci. 2018;18(3):95-117.

17. Mahade S, Curry N, Björklund S, Markocsan N, Nylén P. Engineered thermal barrier coatings deposited by suspension plasma spray. Mater Lett. 2017;209:517-21.

18. Łatka L, Cattini A, Chicot D, Pawłowski L, Kozerski S, Petit F, i in. Mechanical Properties of Yttriaand Ceria-Stabilized Zirconia Coatings Obtained by Suspension Plasma Spraying. J Therm Spray Technol. 2013;22(2):125-30.

19. Oberste Berghaus J, Legoux JG, Moreau C, Hui R, Ghosh D. Suspension Plasma Spraying of Intermediate Temperature SOFC Components Using an Axial Injection DC Torch. Mater Sci Forum. 2007;539-543:1332-7.

20. Waldbillig D, Kesler O. Electrochemical testing of suspension plasma sprayed solid oxide fuel cell electrolytes. J Power Sources. 2011; 196(13):5423-31.

21. Ročňáková I, Slámečka K, Montufar EB, Remešová M, Dyčková L, Břínek A, i in. Deposition of hydroxyapatite and tricalcium phosphate coatings by suspension plasma spraying: Effects of torch speed. J Eur Ceram Soc. 2018;38(16):5489-96. 
22. Łatka L, Pawlowski L, Chicot D, Pierlot C, Petit F. Mechanical properties of suspension plasma sprayed hydroxyapatite coatings submitted to simulated body fluid. Surf Coat Technol. 2010;205(4):954-60.

23. Michalak M, Latka L, Sokolowski P, Toma F-L, Myalska H, Denoirjean A, i in. Microstructural, mechanical and tribological properties of finely grained A12O3 coatings obtained by SPS and SHVOF methods. Surf Coat Technol. 2020;126463.

24. Murray JW, Leva A, Joshi S, Hussain T. Microstructure and wear behaviour of powder and suspension hybrid Al2O3-YSZ coatings. Ceram Int. 2018;44(7):8498-504.

25. Kozerski S, Toma F-L, Pawlowski L, Leupolt B, Latka L, Berger L-M. Suspension plasma sprayed TiO2 coatings using different injectors and their photocatalytic properties. Surf Coat Technol. 2010;205(4):980-6.

26. Robinson BW, Tighe CJ, Gruar RI, Mills A, Parkin IP, Tabecki AK, i in. Suspension plasma sprayed coatings using dilute hydrothermally produced titania feedstocks for photocatalytic applications. J Mater Chem A. 2015;3(24):12680-9.

27. Tarasi F, Alebrahim E, Dolatabadi A, Moreau C. A Comparative Study of YSZ Suspensions and Coatings. Coatings. 2019;9(3):188.

28. Zhou D, Guillon O, Vaßen R. Development of YSZ Thermal Barrier Coatings Using Axial Suspension Plasma Spraying. Coatings. 2017;7(8):120.

29. Caio F, Moreau C. Influence of Substrate Shape and Roughness on Coating Microstructure in Suspension Plasma Spray. Coatings. 2019;9(11):746.

30. Macek W, Wołczański T. Analysis of fracture roughness parameters of $\mathrm{S} 355 \mathrm{~J} 2$ steel and $\mathrm{EN}$ AW-2017A-T4 aluminium alloy. ITM Web Conf. 2017;15:06002.

31. Macek W, Branco R, Szala M, Marciniak Z, Ulewicz R, Sczygiol N, i in. Profile and Areal Surface Parameters for Fatigue Fracture Characterisation. Materials. 2020;13(17):3691.

32. ASTM C1624-05, Standard Test Method for Adhesion Strength and Mechanical Failure Modes of Ceramic Coatings by Quantitative Single Point Scratch Testing, ASTM International, 2010.

33. ASTM G171-03, Standard Test Method for Scratch Hardness of Materials Using a Diamond Stylus, ASTM International, 2003.

34. Oliver WC, Pharr GM. Measurement of hardness and elastic modulus by instrumented indentation: Advances in understanding and refinements to methodology. J Mater Res. 2004;19(1):3-20.

35. Oliver WC, Pharr GM. An improved technique for determining hardness and elastic modulus using load and displacement sensing indentation experiments. J Mater Res. 1992;7(6):1564-83.
36. Lancaster JK. The influence of substrate hardness on the formation and endurance of molybdenum disulphide films. Wear. 1967;10(2):103-17.

37. Kozerski S, Pawlowski L, Jaworski R, Roudet F, Petit F. Two zones microstructure of suspension plasma sprayed hydroxyapatite coatings. Surf Coat Technol. 2010;204(9):1380-7.

38. Łatka L, Chicot D, Cattini A, Pawłowski L, Ambroziak A. Modeling of elastic modulus and hardness determination by indentation of porous yttria stabilized zirconia coatings. Surf Coat Technol. 2013;220:131-9.

39. Szala M, Łatka L, Walczak M, Winnicki M. Comparative Study on the Cavitation Erosion and Sliding Wear of Cold-Sprayed $\mathrm{Al} / \mathrm{Al} 2 \mathrm{O} 3$ and $\mathrm{Cu} /$ Al2O3 Coatings, and Stainless Steel, Aluminium Alloy, Copper and Brass. Metals. 2020;10(7):856.

40. Szala M, Walczak M, Łatka L, Gancarczyk K, Özkan D. Cavitation Erosion and Sliding Wear of MCrAlY and NiCrMo Coatings Deposited by HVOF Thermal Spraying. Adv Mater Sci. 2020;20(2):26-38.

41. Żebrowski R, Walczak M. Effect of the Shot Peening on Surface Properties and Tribological Performance of Ti-6Al-4V Alloy Produced by Means of DMLS Technology. Arch Metall Mater. 2019;64(1):377-83.

42. Drozd K, Walczak M, Szala M, Gancarczyk K. Tribological behaviour of AlCrSiN-coated tool steel K340 versus popular tool steel grades. Materials. 2020;13:4895.

43. Szala M, Dudek A, Maruszczyk A, Walczak M, Chmiel J, Kowal M. Effect of atmospheric plasma sprayed $\mathrm{TiO} 2-10 \% \mathrm{NiAl}$ cermet coating thickness on cavitation erosion, sliding and abrasive wear resistance. Acta Phys Pol A. 2019;136(2):335-41.

44. Michalak M, Latka L, Szala M, Walczak M, Sokolowski P, Ambroziak A. Investigations of $\mathrm{TiO} 2$ addition in alumina-titania APS sprayed coatings on sliding wear and cavitation erosion resistance. Surf Coat Technol. 2021:In print.

45. Szala M, Szafran M, Macek W, Marchenko S, Hejwowski T. Abrasion Resistance of S235, S355, C45, AISI 304 and Hardox 500 Steels with Usage of Garnet, Corundum and Carborundum Abrasives. Adv Sci Technol Res J. 2019;13(4):151-161.

46. Darut G, Ageorges H, Denoirjean A, Fauchais P. Tribological performances of YSZ composite coatings manufactured by suspension plasma spraying. Surf Coat Technol. 2013;217:172-80.

47. Yan H, Zhao L, Chen Z, Hu X, Yan Z. Investigation of the Surface Properties and Wear Properties of AISI H11 Steel Treated by Auxiliary Heating Plasma Nitriding. Coatings. 2020;10(6):528.

48. Stachowiak G, Batchelor AW. Engineering Tribology. 4 edition. Butterworth-Heinemann; 2016. 884 p. 